\title{
Differential seed maturation uncouples fertilization and siring success in Oenothera organensis (Onagraceae)
}

\author{
KAYRI HAVENS* \& LYNDA F. DELPH \\ Department of Biology, Indiana University, Bloomington, IN 47405, U.S.A.
}

\begin{abstract}
This study examines ovule fertilization and seed maturation success in an evening primrose, Oenothera organensis, using transgenic plants. The reproductive success of several pollen donors was compared using individuals transformed with the GUS ( $\beta$-glucuronidase) marker gene which allowed the genotype of developing ovules to be determined prior to seed abortion. This marker gene allowed us to discriminate between a pollen donor's success in fertilizing ovules and its success in siring seeds. Transformed plants had decreased microgametophytic vigour, as evidenced by lower than expected fertilization success in vivo and slower pollen tube growth rates in vitro. However, transformation had no apparent effect on offspring sporophytic vigour, including seed mass, seedling emergence and dry weight. This illustrates the effectiveness of fertilization competition in screening out poorly functioning haploid genomes as suggested by Mulcahy (1979). We found significant differences between the percentage of ovules fertilized and the percentage of seeds sired by a pollen donor in four of eight cases. Hence, fertilization success does not always predict seed paternity. The proportion of seeds sired by the transformed donor with very low fertilization success increased, whereas the proportion sired by the donor with relatively high fertilization success was reduced. This resulted in nearly equal siring ability for the two donors in spite of their difference in fertilization ability.
\end{abstract}

Keywords: fertilization success, gametophytic selection, paternity analysis, seed abortion, seed maturation, sporophytic vigour.

\section{Introduction}

In angiosperms, pollen-donating plants can differ in their reproductive success at several stages, including pollination, fertilization, seed maturation, and seedling establishment (Lyons et al., 1989). If heritable variation exists for traits that confer success at any of these stages, evolutionary change can result. A number of traits can affect a plant's success in siring offspring. Flower number is correlated with pollen donation in Oenothera organensis (Havens, 1994a) and with the number of seeds sired in Asclepias exaltata (Broyles \& Wyatt, 1990). Pollen production and/or corolla size are both known to be correlated with pollen export (Young \& Stanton, 1990; Campbell et al., 1991; Stanton et al., 1992) and paternity success (Schoen \& Stewart, 1986).

After pollen arrives on a receptive stigma, fertili-

*Correspondence: Missouri Botanical Garden, PO Box 299, St Louis, MO 63166, U.S.A. zation competition can occur if the amount of viable pollen deposited exceeds the number of ovules in the ovary. Pollen tube growth rate is one trait that potentially influences a pollen donor's success in fertilization competition. Many studies have found variation in pollen tube growth rates, both in vitro (Schemske \& Fenster, 1983; Stephenson \& Bertin, 1983) and in vivo (Bertin, 1982, 1985; Marshall \& Ellstrand, 1986; Snow \& Mazer, 1988). Snow \& Spira (1991) have shown that pollen tube growth rate is correlated with the number of seeds sired in Hibiscus moscheutos. Stephenson et al. (1992) have shown that two Cucurbita pepo (zucchini) cultivars differ in pollen performance, which results in nonrandom fertilization. Also in C. pepo, a study by Quesada et al. (1993) indicated that progeny sired by the fastest pollen tubes outperform that sired by the slowest. Mulcahy et al. (1983) found that pollen tube growth rates differ significantly in a natural population of Geranium maculatum; they also found that pollen tube competition occurs both between pollen 
grains that reach the stigma simultaneously, as well as between those of separate pollinations. In a frequently cited paper, Mulcahy (1979) suggested that the combination of insect pollination and closed carpels in the early angiosperms intensified fertilization competition, thus screening out poorly functioning genomes. In other words, when fertilization competition occurs, selection could discriminate against individuals with deleterious mutations in the haploid, gametophytic stage at little cost compared to selection on the diploid, sporophytic stage of the life cycle.

Patterns of seed maturation can also be decidedly nonrandom. Seed abortion can be related to many factors, including time of seed initiation, position of seed within the fruit, time of fruit initiation, position of fruit and pollen source. Seed maturation patterns can enhance the fitness of the maternal plant, its offspring, or both (Lee, 1988; Rocha \& Stephenson, 1991). Many authors suggest that selection will favour plants that differentially mature offspring of high quality (Willson, 1979; Stephenson, 1981; Bertin, 1982). Fruits initiated under heavy pollination may contain seeds of higher quality because of a high level of gametophyte competition (Mulcahy, 1979). In Lotus corniculatus, for example, fruits containing seeds initiated in the absence of gametophyte competition or seeds resulting from self-fertilization were more likely to abort. This abortion pattern resulted in offspring that were more likely to germinate and more vigorous than those derived from experimental random abortion (Stephenson \& Winsor, 1986). Bookman (1984) demonstrated that fruit abortion in Asclepias was nonrandom and at least partially the result of competition among pollen donors. In Raphanus sativus, multiply sired fruits were heavier than those sired by a single donor and less likely to abort (Marshall \& Ellstrand, 1986; Marshall, 1988).

Nonrandom reproductive success has been documented extensively in plants. However, a comprehensive study examining the success of individuals at each reproductive stage has not yet been undertaken (Lyons et al., 1989). The purpose of this study was to determine the effects of pollen donor identity on fertilization, seed maturation, and seedling establishment success in $O$. organensis. A genetically engineered marker gene, GUS ( $\beta$-glucuronidase), was used to determine paternity in mixed pollinations. This marker allowed paternity to be determined at any stage of the life cycle, including very young embryos, mature seeds and mature sporophytes. Therefore, a pollen donor's success in fertilizing ovules could be examined independently from its success in seed siring. Differential siring success has been suggested to be, in part, a result of post-fertilization events (Rigney et al., 1993). Here, our ability to determine the paternity of fertilized ovules prior to seed abortion allowed us to test this hypothesis directly.

\section{Materials and methods}

Oenothera organensis is a herbaceous, self-incompatible perennial that is a rare endemic of the Organ Mountains of New Mexico. Plants typically open several hawkmoth-pollinated flowers each evening, which senesce by noon the following day. Each flower generally receives more than enough pollen to ensure full seed-set within the $\approx 2 \mathrm{~h}$ period of moth activity each night (Havens, 1994a). This suggests that fertilization competition may occur frequently in nature. This species also has an extremely long style $(\approx 25 \mathrm{~cm})$ which should increase the likelihood that small differences in pollen tube growth rate affect fertilization ability (Mulcahy, 1971). Oenothera organensis has a gametophytic selfincompatibility system (Emerson, 1940) and the plants used in this study were from a population maintained at Indiana University. The university population consists of several hundred individuals representing five characterized self-incompatibility alleles. These plants originated from cuttings taken in the wild in the 1940s. Because the species is a long-lived perennial and plants are usually propagated asexually, the university population has gone through relatively few generations since its collection.

\section{Transformations}

Plants of several self-incompatibility $(S)$ genotypes were transformed using a system mediated by Agrobacterium tumefaciens developed by Scelonge (1989). The transformation construct consisted of the cauliflower mosaic virus (CaMV) 35S promoter fused to the GUS ( $\beta$-glucuronidase) reporter gene provided by R. Jefferson (see Jefferson et al., 1987). Plants transformed with the CaMV-GUS construct express GUS in most tissues, including the heart-stage and earlier embryos fertilized by pollen from transformed plants (personal observation). For this study, embryos were assayed at the late torpedo or early cotyledon stage, well after GUS expression began. The transformation protocol usually results in more than one transferred DNA (the portion of the bacterial DNA that is integrated into the nuclear genome of the plant cell; T-DNA) insertion

(c) The Genetical Society of Great Britain, Heredity, 76, 623-632. 
(Scelonge, 1989), so most of the pollen produced by transformed plants should carry the GUS gene. The proportion of pollen carrying GUS was estimated for each plant by performing single-donor pollinations.

\section{Fertilization and seed maturation success}

Pollen from transformed pollen donors was applied to the stigmas of nontransformed pollen recipients, alone, or with pollen from a nontransformed donor of the same S-genotype as the transformed donor. For single-donor pollinations, the contents of two anthers from a single flower were brushed on to the stigma. For two-donor pollinations, the contents of one anther from each of the two donors were used, each applied to one half of the stigma simultaneously. This resulted in the application of nearly equal amounts of pollen from the two donors. In this species, the style is not partitioned so pollen tubes from all four lobes of the stigma can mix in the style and fertilize ovules in any of the four locules (personal observation). Each anther contains 2000-2500 pollen grains (Lewis, 1948), so pollen was provided in vast excess of that needed to fertilize the $\approx 250-300$ ovules. The pollinations were paired on the same recipient plant, so that on a given day two identical crosses were performed, one to assess the success of fertilization and the other that of seed maturation. Each pollen donor $\times$ recipient cross was replicated three to five times per stage (ovule fertilization or seed maturation), for a total of 108 crosses. Three sets (one set of each $S$-genotype) of two to four genetically identical clones were used for pollen recipients. Plants were distributed randomly on the greenhouse bench and were kept under long-day conditions (16 h light: $8 \mathrm{~h}$ darkness) in order to maintain flowering.

The crossing design is outlined in Table 1. Genotype A represents plants of self-incompatibility $(S)$ genotype $3 / 27$, B represents $S$-genotype $4 / 27$, and C represents $S$-genotype 27/28. All the crosses were half-compatible, meaning that only pollen grains carrying the 3,4 , or 28 allele would grow down the style. Crosses using a B genotype transformed donor on recipients of $\mathrm{A}$ and $\mathrm{C}$ genotypes were also performed. However, the B donor failed to fertilize any ovules or sire any seed that expressed GUS. This could have been caused by the T-DNA insertion being linked to the $S$-locus in this plant, or the T-DNA insertion interrupting a gene necessary for gametophytic development and therefore lethal in the haploid stage.

Fertilization success was assayed 10 days after
Table 1 Crossing design for fertilization and seed maturation success experiment. A, B and C represent selfincompatibility $(S)$ genotypes. The pollen recipients were sets of genetically identical clones (2-4 plants per $S$-genotype). The pollen donors were genetically unique; plants with the same letter share the same $S$-genotype. C1 and $\mathrm{A} 1$ are the transformed donors; all the other plants are nontransformed. Simultaneous pollinations are indicated by the two donors separated by a solidus (/)

\begin{tabular}{|c|c|}
\hline Donor & Recipient \\
\hline $\mathrm{C} 1$ & A \\
\hline $\mathrm{C} 1 / \mathrm{C} 2$ & A \\
\hline $\mathrm{C} 1 / \mathrm{C} 3$ & A \\
\hline $\mathrm{C} 1 / \mathrm{C} 4$ & A \\
\hline $\mathrm{C} 1$ & B \\
\hline $\mathrm{C} 1 / \mathrm{C} 2$ & B \\
\hline $\mathrm{C} 1 / \mathrm{C} 3$ & B \\
\hline $\mathrm{C} 1 / \mathrm{C} 4$ & B \\
\hline A1 & B \\
\hline $\mathrm{A} 1 / \mathrm{A} 2$ & B \\
\hline A1/A3 & B \\
\hline A1/A4 & B \\
\hline A1 & $\mathrm{C}$ \\
\hline $\mathrm{A} 1 / \mathrm{A} 2$ & $\mathrm{C}$ \\
\hline A1/A3 & $\mathrm{C}$ \\
\hline A1/A4 & $\mathrm{C}$ \\
\hline
\end{tabular}

pollination, before the majority of seed abortion occurs in this species (less than 0.5 per cent of seeds aborted before 16 days postpollination, whereas $\approx 10$ per cent of seeds were aborted by fruit maturity at 60 days postpollination; aborted seeds were markedly smaller than maturing seeds). Fruits were harvested, and $\approx 50$ embryos per fruit were dissected out of the immature seeds (for a total of 2800 embryos) and assayed histologically for GUS expression (Jefferson, 1987). Paternity of viable seeds was determined at fruit maturity, six weeks after pollination. All of the seeds in each fruit (seed number ranged from 21 to 270 , mean $=193$ per fruit, for a total of 9842 seeds assayed) were germinated on moist filter paper, and the hypocotyls and radicles were excised and assayed for GUS expression.

\section{Seedling establishment}

After the fruits for the previous experiment were harvested, an additional set of single-donor crosses was used to determine the effects of transformation on sporophyte characters involved in seedling establishment success. For each of the four possible crosses (A1 transformed donor on recipient $\mathrm{B}, \mathrm{A} 1$ 
on $\mathrm{C}, \mathrm{C} 1$ on $\mathrm{A}, \mathrm{C} 1$ on $\mathrm{B}$ ), two replicate pollinations were performed as described above and the seeds were allowed to mature. All of the seeds from each fruit were weighed individually, and then were planted in seedling trays $(25 \times 25 \times 70 \mathrm{~mm})$. Date of emergence was recorded for each seed. After eight weeks, all of the plants were harvested, a root was excised from each plant for GUS assays, and the dry weight of the above ground portion of the plant was determined. A total of 56 transformed and 49 nontransformed offspring (null segregants) were measured.

\section{Pollen tube growth rates}

Pollen tubes of both the transformed and four of the six nontransformed donors were grown in vitro on Kwack's pollen germination medium with 1 per cent agarose (Brewbaker \& Kwack, 1963) and measured with an image digitizer after $2 \mathrm{~h}$ as described by Havens (1994b). For each genotype, 20 pollen tubes from each of four to eight flowers were measured.

\section{Data analysis}

The expected performance of the transformed donors was calculated as one half of the percentage offspring expressing GUS when these plants were the sole pollen donor. Not all of the offspring of a transformed plant will express GUS because the transformation procedure does not result in a T-DNA insertion on every chromosome. Therefore, GUS expression will segregate in the offspring, and the segregation ratio will depend on the number of T-DNA insertions. This segregation ratio was determined for each of the transformed plants using single-donor pollinations. A comparison of the ability of donors to fertilize ovules and sire seeds was undertaken using separate MANOVAs for A and $\mathrm{C}$ donors, because of the interdependence of the two dependent variables (fertilization success and seed siring success). To meet parametric assumptions, the percentage of ovules fertilized and seeds sired were arcsin-square-root transformed prior to analysis. We performed univariate ANOVAs on each dependent variable, which indicated that donors differed in their fertilization ability. Therefore, in order to determine which donors differed from each other, we performed planned contrasts for fertilization success between the transformed and nontransformed pollen donors and between the most different nontransformed donor and the other two nontransformed donors. Pearson correlation coefficients were calculated to determine whether fertili- zation ability and seed siring ability were significantly correlated. In addition, a two-way ANOVA was performed for each set of pollen donors (A or C), with percentage reproductive success (i.e. either percentage of ovules fertilized or seed sired) as the dependent variable and stage (fertilization or seed maturation) and cross as the main effects. The stage $\times$ cross interactions were nonsignificant ( $P>0.25$ in both cases), indicating that the effect of stage did not differ across crosses for either set of pollen donors, and were therefore left out of the models. Comparisons within crosses between stages were made using the one-way ANOVA approach outlined by McKone \& Lively (1993).

Differences in the percentage of offspring expressing GUS were also analysed with respect to maternal parent genotype using a one-way ANOVA for each stage (i.e. fertilization and seed maturation). Data were transformed as above prior to analysis.

In the seedling establishment experiment, transformed offspring were compared to null segregants within each cross for seed mass, date of emergence and seedling dry weight using $t$-tests. In the one instance when variances differed significantly, a Kruskal-Wallace test was also performed.

\section{Results}

Neither of the transformed donors' reproductive success differed significantly on the two recipient genotypes pollinated, so results were pooled across recipients for each donor. Both transformed donors, $\mathrm{A} 1$ and $\mathrm{C} 1$, fertilized fewer ovules and sired fewer seeds than expected when paired with nontransformed donors (Fig. 1, Table 2). The fertilization success of the nontransformed donors did not differ significantly (Table 2).

The main effect stage was significant for the crosses involving both $\mathrm{A}$ and $\mathrm{C}$ pollen donors (two-way ANOVAs, see Table 3). In all cases, the A1 transformed donor had a higher percentage of seeds sired than ovules fertilized and in one case this difference was significant (Table 3 and Fig. 1). The correlation between these traits was not significant $(r=0.034, \quad P=0.949, \quad n=6)$. A1 fertilized, on average, only 4.9 per cent of the ovules but sired 11.9 per cent of the seeds. In contrast to $\mathrm{A} 1$, the $\mathrm{C} 1$ transformed donor was more successful in fertilizing ovules than in siring seeds, a difference which was significant in three out of four cases. Once again, the correlation between these two performance traits was nonsignificant $(r=0.19, P=0.721, n=6)$. The average percentage of ovules fertilized by $\mathrm{C} 1$ was 


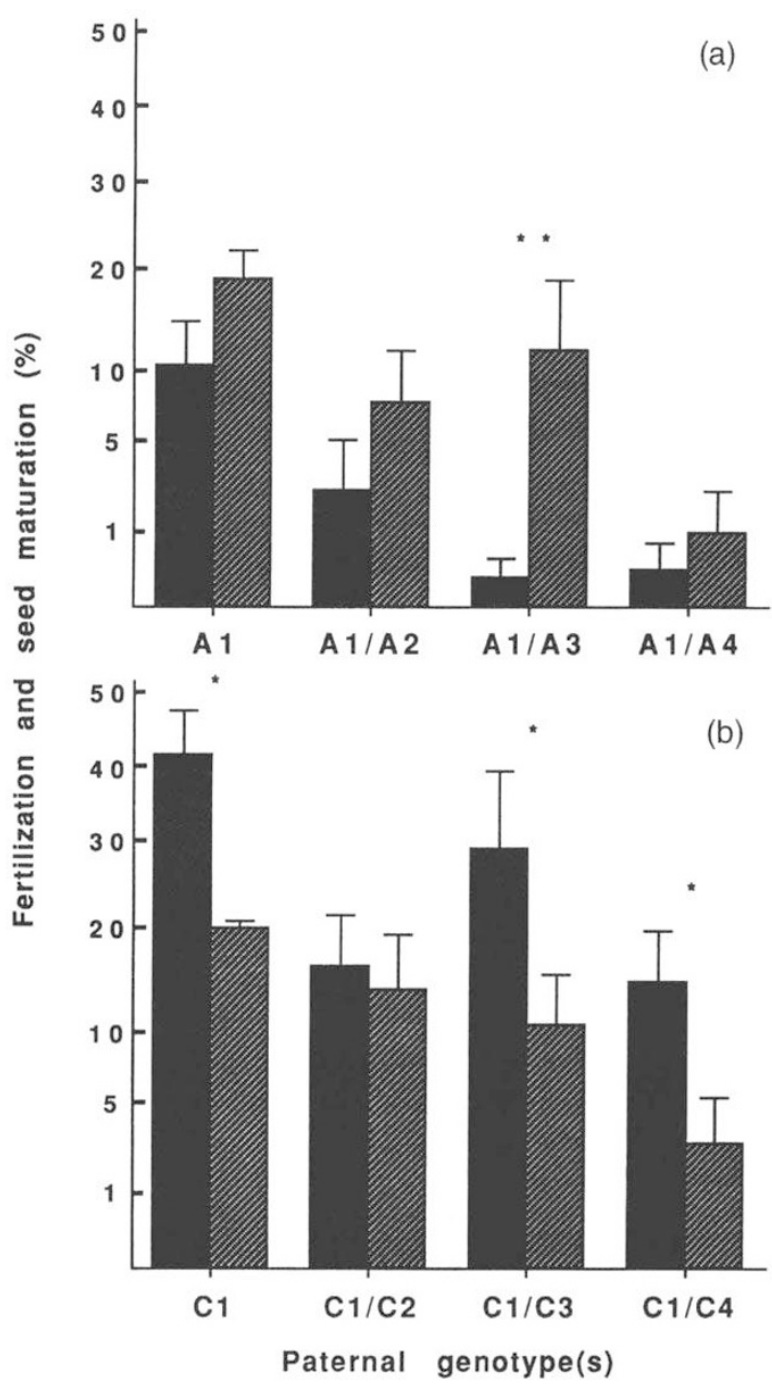

Fig. 1 The mean $( \pm S E)$ percentage of ovules fertilized (solid bars; $n$ ranges from 6 to 9 ) and seeds sired (hatched bars; $n$ ranges from 6 to 8 ) in Oenothera organensis by (a) transformed donor $\mathrm{C} 1$ and (b) transformed donor A1, in competition with three nontransformed donors (reproductive success on two maternal genotypes pooled). In both (a) and (b), the first pair of columns shows the expected success of the transformed donor ( $\mathrm{C} 1$ or $\mathrm{A} 1$ ) based on single-donor pollinations (i.e. half of the percentage when it was the sole pollen donor). See Tables 2 and 3 for MANOVA and ANOVA summaries. Significant differences between stages within each cross are indicated by asterisks $\left({ }^{*} P<0.05,{ }^{* *} P<0.01\right)$. The data are arcsin-square-root transformed, with the vertical axes backtransformed to percentages for ease of viewing.

22.1 per cent as opposed to only 13.5 per cent seeds sired.

Seed abortion patterns resulted in multiple paternity of the seed crop (Fig. 1). Note that the transformed donor with the relatively high fertilization
Table 2 Results of separate manovas and ANovas with orthogonal contrasts comparing in Oenothera organenesis fertilization success and seed siring success across donors, for crosses involving either $\mathrm{A}$ or $\mathrm{C}$ pollen donors. $\mathrm{C} 1$ and $\mathrm{A} 1$ are the transformed donors; all the other plants are nontransformed. Dependent variables are percentage of ovules fertilized and percentage of seeds sired (both were arcsin-square-root transformed prior to analysis)

\begin{tabular}{|c|c|c|c|}
\hline & $F$ & d.f. & $P$ \\
\hline \multicolumn{4}{|l|}{ MANOVAS (Wilks's criterion) } \\
\hline A crosses & 3.97 & 6,40 & 0.003 \\
\hline $\mathrm{C}$ crosses & 4.09 & 6,38 & 0.003 \\
\hline \multicolumn{4}{|l|}{ ANOVAS } \\
\hline \multicolumn{4}{|c|}{ Crosses with A pollen donors } \\
\hline Fertilization & 5.21 & 3 & $0.008^{*}$ \\
\hline Seed siring & 3.31 & 3 & $0.040^{*}$ \\
\hline \multicolumn{4}{|c|}{ Crosses with $\mathrm{C}$ pollen donors } \\
\hline Fertilization & 4.07 & 3 & $0.021^{*}$ \\
\hline Seed siring & 3.99 & 3 & $0.022 *$ \\
\hline \multicolumn{4}{|l|}{ Orthogonal Contrasts } \\
\hline $\mathrm{A} 1$ vs. $\mathrm{A} 2, \mathrm{~A} 3$ and $\mathrm{A} 4$ & 15.23 & 1 & $0.001^{*}$ \\
\hline $\mathrm{A} 2$ vs. $\mathrm{A} 3$ and $\mathrm{A} 4$ & 1.29 & 1 & 0.270 \\
\hline $\mathrm{C} 1$ vs. $\mathrm{C} 2, \mathrm{C} 3$ and $\mathrm{C} 4$ & 6.49 & 1 & $0.019^{*}$ \\
\hline $\mathrm{C} 3$ vs. $\mathrm{C} 2$ and $\mathrm{C} 4$ & 1.88 & 1 & 0.186 \\
\hline
\end{tabular}

*Significance level for univariate tests is 0.025 for the most significant difference and 0.05 for the second difference (sequential Bonferroni adjustment for two dependent variables; see Rice, 1989).

success $(\mathrm{C} 1)$ showed a reduction in success between the stages of fertilization and seed maturation, whereas the opposite was true for the other transformed donor (A1). So although average fertilization success differed by 17.3 per cent between the two donors, seed siring success varied by only 1.6 per cent.

A lack of difference in seed siring success was also observed when the crosses were analysed with respect to recipient genotype (Fig. 2). Significant differences were found between recipients in the percentage of ovules fertilized by a transformed donor (one-way ANOVA; $F_{2,54}=9.78, \quad P<0.001$ ), which were likely to have been caused by differences between transformed donors in the number of pollen grains carrying the GUS gene. Transformed males fertilized only 4 per cent of the ovules on females of genotype C, but nearly 30 per cent of those on females of genotype A (Fig. 2). In contrast, there were no differences in the number of seeds sired by transformants (one-way ANOVA; $F_{2,49}=0.68$, $P=0.511)$. Mean seed siring percentages differed by only 2.9 per cent. 
Table 3 Results of two-way anovas in Oenothera organensis for the effect of cross and stage (fertilization vs. seed maturation) on the percentage reproductive success of $\mathrm{A}$ and $\mathrm{C}$ pollen donors (see Fig. 1)

\begin{tabular}{lcccc}
\hline Source & d.f. & $M S$ & $F$ & $P$ \\
\hline A pollen donors & & & & \\
$\quad$ Cross & 3 & 0.240 & 8.9 & $<0.001$ \\
$\quad$ Stage & 1 & 0.309 & 11.6 & $<0.001$ \\
$\quad$ Stage effect comparisons within each cross & & & & \\
$\quad$ within cross 1 & 1 & 0.062 & 2.3 & $>0.10$ \\
$\quad$ within cross 2 & 1 & 0.052 & 1.9 & $>0.10$ \\
$\quad$ within cross 3 & 1 & 0.311 & 11.5 & $<0.0025$ \\
$\quad$ within cross 4 & 1 & 0.006 & 0.2 & $>0.25$ \\
Error & 50 & 0.027 & & \\
C pollen donors & & & & \\
$\quad$ Cross & 3 & 0.181 & 5.0 & 0.004 \\
$\quad$ Stage & 1 & 0.403 & 11.2 & 0.002 \\
Stage effect comparisons within each cross & & & & \\
$\quad$ within cross 1 & 1 & 0.177 & 4.9 & $<0.05$ \\
$\quad$ within cross 2 & 1 & 0.002 & 0.1 & $>0.50$ \\
$\quad$ within cross 3 & 1 & 0.204 & 5.7 & $<0.025$ \\
$\quad$ within cross 4 & 1 & 0.144 & 4.0 & 0.05 \\
$\quad$ Error & 48 & 0.036 & & \\
\hline
\end{tabular}

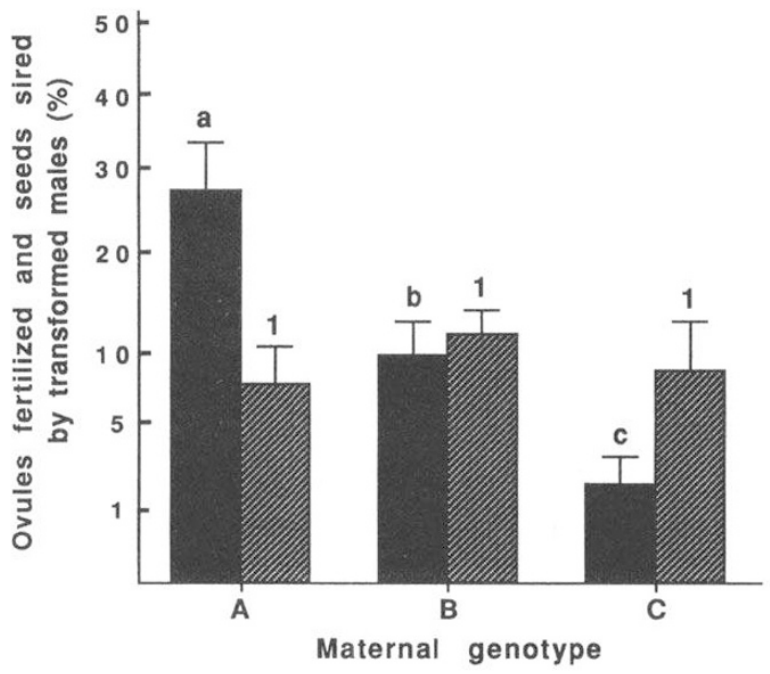

Fig. 2 The mean $( \pm S E)$ percentage of ovules fertilized (solid bars) and seeds sired (hatched bars) by transformed donors on the three maternal genotypes of Oenothera organensis. Significant differences $(P<0.05)$ between genotypes are indicated by different letters or numbers (Tukey's a posteriori comparison). $n$ ranges from 12 to 30 . The data are arcsin-square-root transformed, with the vertical axes backtransformed to percentages for ease of viewing.

Pollen tube growth rates in vitro were similar to those suggested by the different rates of fertilization success. Rates of the two transformed donors were always slower than those of nontransformed donors and in two cases this difference was significant (one-way ANOvA; $F_{5,26}=7.51, P<0.001$; Fig. 3 ). Of the pollen donors with genotype $\mathrm{A}$, plant $\mathrm{A} 3 \mathrm{had}$ the fastest pollen tube growth rate in vitro, and also performed best in competition with that of the transformed donor in vivo (Fig. 1). Similarly, significant differences between in vitro growth rates of transformant $\mathrm{C} 1$ and nontransformed $\mathrm{C} 2$ translated into differences in fertilization performance in vivo (Fig. 1).

Transformants and null segregants (those fertilized by pollen from nontransformed plants) did not differ significantly in seed mass, date of germination, or seedling dry mass in any of the four crosses (Fig. 4).

\section{Discussion}

The results of this study support two hypotheses: siring success is determined partly by fertilization success, which is in turn a function of pollen tube growth rates, and also partly by postfertilization events. In all the crosses where a transformed plant was paired with a nontransformed plant, the transformant fertilized fewer ovules than predicted. Transformants also had correspondingly slower pollen tube growth rates in vitro. It is possible that the T-DNA insertions may have interrupted genes expressed in the gametophytic generation, causing these microgametophytes to be less vigorous than 


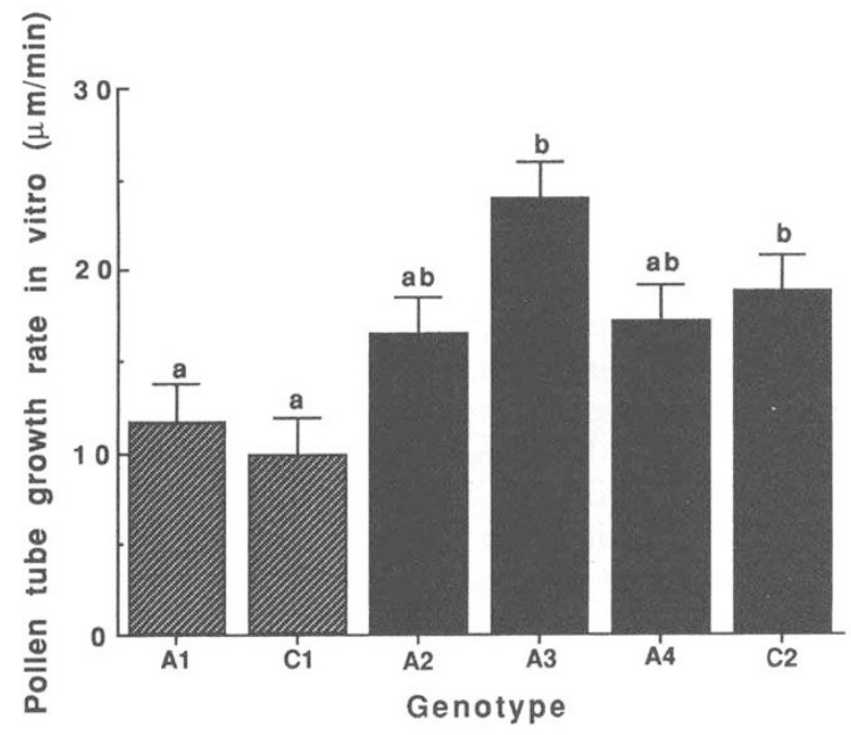

Fig .3 Mean ( $\pm S E)$ in vitro pollen tube growth rates of the two transformed donors (A1 and C1) and several nontransformed donors of Oenothera organensis. Significant differences $(P<0.05)$ between genotypes are indicated by different letters (Tukey's a posteriori comparison). $n$ ranges from 4 to 8 .

those from nontransformed plants. If this is the case, one could consider these T-DNA insertions to be analogous to recessive deleterious mutations that are exposed to selection in the haploid generation, but protected in the sporophyte. Alternatively, expression of another gene on the T-DNA plasmid, such as antibiotic resistance, could account for the decreased vigour if the gene product somehow interferes with gametophytic development. In this study, as in others (Jefferson et al., 1987), the transformed sporophytes appear normal and healthy and no adverse effects of the transformation procedure were noticed. In addition, offspring of the transformants that carried the GUS gene were no less vigorous than the nontransformed null segregants on several measures of seedling establishment. In other words, transformation, like a mutation, affected properties of the gametophyte in such a way as to make it less vigorous, but had no apparent effect on the diploid sporophyte. This was probably caused by the transformation being masked by genes contributed by the maternal plant and illustrates the effectiveness of gametophytic selection in screening out poorly functioning haploid individuals (Mulcahy, 1979).

Despite the limitations imposed by the deleterious effects of transformation on the gametophytic generation, this system can still be used to assess the relative contribution of nontransformed donors
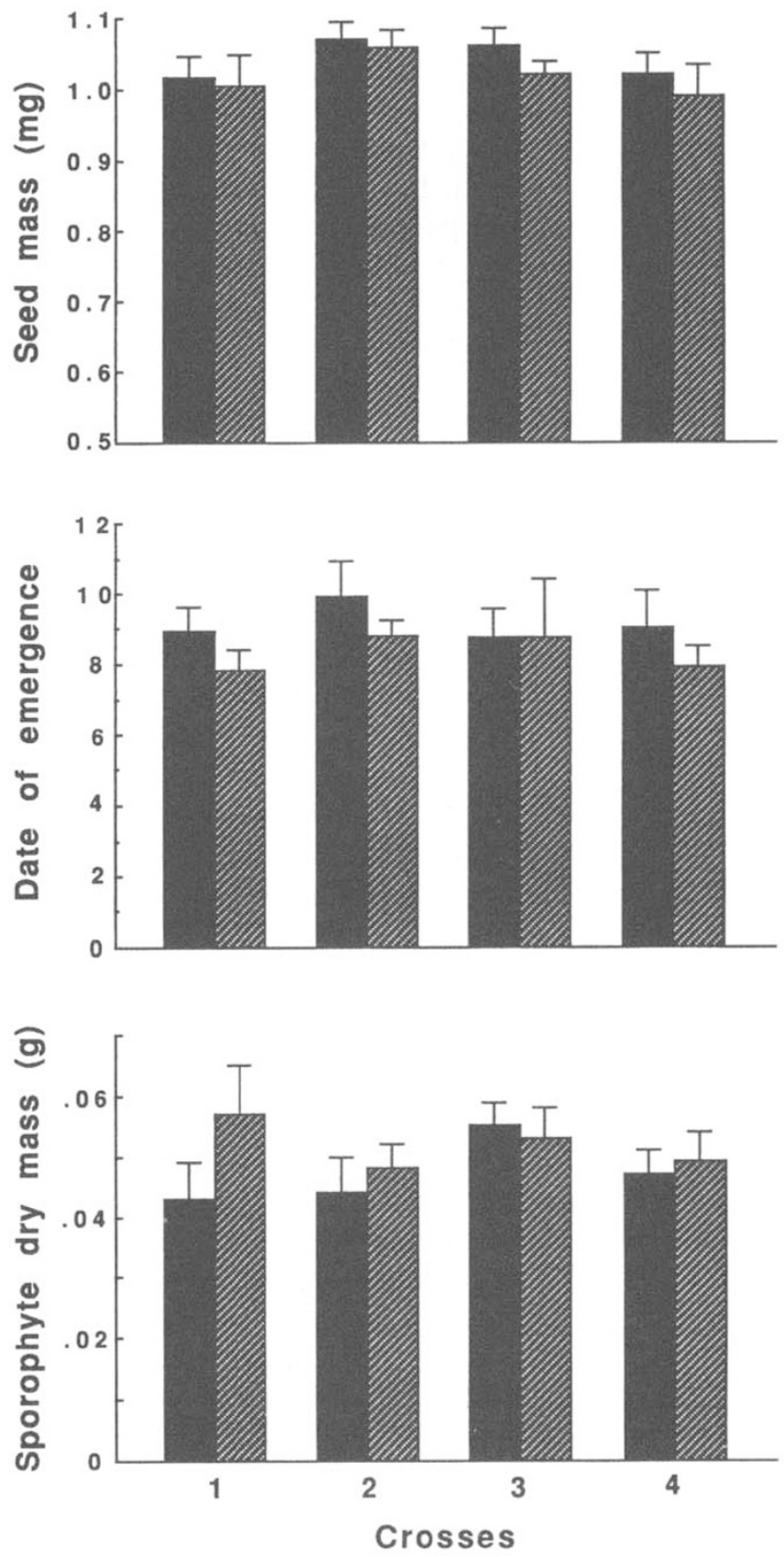

Fig. 4 Differences between transformed (solid bars) and nontransformed (hatched bars) offspring from each of four crosses for three measures of seedling establishment in Oenothera organensis. None of the differences is significant $(P>0.05) . n$ ranges from 9 to 19 .

against the transformed donor standard. This method (comparing individuals against a standard pollen donor with a genetic marker) has been used frequently in pollen competition studies, particularly on maize (Ottaviano et al., 1983; Landi \& Frascaroli, 1988). The method assumes that pollen tubes do not interact in the style, or, that if they do, the standard 
pollen donor affects pollen tubes from other donors in the same way, either enhancing or inhibiting their growth to a similar extent. Some studies have suggested that pollen tubes interact (Aizen et al., 1990; Cruzan, 1990a), but this is usually the result of incompatibility phenomena such as cryptic self-incompatibility (reviewed by Barrett, 1988) or the mentor effect, i.e. fertilization by normally incompatible pollen when compatible pollen is also present (Visser, 1983). In O. organensis, the incompatibility system is well-characterized and the $S$-genotype of all the plants used in this study was known. When comparing the fertilization success of the two sets of nontransformed plants in this study, none of the plants within a set differed significantly in fertilization ability. This is not surprising given the results of a previous study which suggested that heritable variation of pollen tube growth rate in this species is less than 9 per cent (Havens, 1994b).

In the present study, in vitro pollen tube growth rate was a good predictor of in vivo fertilization ability. Plant A3 had the fastest pollen tube growth rate in vitro and it also had the highest fertilization success of any of the nontransformed A donors in competition with A1. In addition, the two transformants had the slowest growth rates in vitro, and they consistently fertilized fewer ovules than expected against all the nontransformed donors. Although some studies have found a reasonable correlation between in vivo and in vitro rates (Barnes \& Cleveland, 1963; Sari Gorla et al., 1975), others have not found this to be the case (Pfahler \& Linskens, 1972; Dane \& Melton, 1973; Mazer, 1987). However, though some researchers have inferred in vivo rates from the number of seeds sired, this study shows that there can be significant differences between the percentage of ovules fertilized by a particular individual and the percentage seeds sired by that individual.

When the percentages of ovules fertilized by transformants were analysed with respect to maternal genotype, significant differences were found. This reflects the fact that the transformed donors differ in the number of pollen grains carrying the GUS gene, which is a function of the number of T-DNA insertions each received rather than some aspect of the maternal genotype. These differences among transformed donors in the proportion of their pollen grains that carried the transformation can be seen by comparing the percentages of transformed embryos resulting from the single-donor pollinations ( 84 per cent vs. 25 per cent, respectively, for $\mathrm{C} 1$ and $\mathrm{A} 1$ ). Thus, the differences seen at the fertilization stage are not an aspect of the maternal genotype.

The most important finding of our study was that there were significant differences between the percentage of ovules fertilized and the percentage of seeds sired by a donor, leading to nonsignificant correlations between success in the two stages. Thus, differential seed maturation must be occurring. Overall, the variance in number of seeds sired was far less than the variance in number of ovules fertilized (variance for seeds sired $=113.3$, variance for ovules fertilized $=325.5$ ), so seed abortion patterns resulted in a similar proportion of seeds expressing GUS across all donor and recipient genotypes. This pattern of seed maturation results in a more similar paternity of the seed crop than would be predicted from fertilization success. In crosses where A1 was the transformed parent, very few of the fertilized ovules expressed GUS. However, differential abortion increased the proportion of seeds that expressed GUS, thereby maintaining a significant portion of the seed crop that was sired by the less successful pollen donor. Conversely, in crosses where $\mathrm{C} 1$ was the transformed parent a higher percentage of the fertilized ovules expressed GUS, and in these crosses GUS offspring were selectively aborted. Overall, 50 per cent of the crosses showed a significant difference between fertilization success and seed siring success.

This is different from a mechanism promoting multiple paternity in wild radish where multiply sired fruits are selectively matured. In the case of wild radish, abortion patterns leading to multiple paternity have been shown at the level of the entire fruit rather than individual seeds (Marshall, 1988). More analogous to our results, are those of Cruzan (1990b), who demonstrated differences among pollen donors of Erythronium grandiflorum in their postfertilization seed siring ability. He found that when donors that were more successful in seed siring (those with large pollen) fertilized ovules, there was increased seed abortion in the same ovary of ovules fertilized by a second donor. Additional evidence for selective abortion related to the pollen donor genotype is scanty, except in cases where both seed abortion and nonrandom fertilization are related to ovule position in the fruit (Lee \& Bazzaz, 1986; Marshall \& Ellstrand, 1988; Nakamura, 1988). In $O$. organensis, no patterns of seed abortion related to position were found (personal observation). The results of this study support the assertion that postfertilization events can have a significant effect on the proportion of seeds sired, and therefore, in species where seed abortion occurs, success 
in siring seeds may not necessarily reflect success in fertilization competition (Charlesworth, 1988; Walsh \& Charlesworth, 1992).

\section{Acknowledgements}

This research was supported by grants from the Indiana Academy of Sciences and the Department of Biology at Indiana University to K. H., and National Science Foundation Grants BSR-9010556 and DEB-9319002 to L. D. Our thanks to P. Swedeen for transforming plants, R. Jefferson for providing us with the GUS construct, and K. Muskavitch, M. Crouch, G. Gastony, L. Rieseberg, A. Stephenson, L. Rigney, D. Campbell, C. Lively and two anonymous reviewers for comments on the project and/or manuscript.

\section{References}

AIZEN, M. A., SEARCY, K. B. AND MUlCAHY, D. L. 1990. Among- and within-flower comparisons of pollen tube growth following self- and cross-pollinations in Dianthus chinensis (Caryophyllaceae). Am. J. Bot., 66, 591-600.

BARNES, D. K., AND CLEVELAND, R. w. 1963. Genetic evidence for nonrandom fertilization in alfalfa as influenced by differential pollen tube growth. Crop Sci., 3, 295-297.

BARRETT, S. C. H. 1988. The evolution, maintenance, and loss of self-incompatibility systems. In: Lovett Doust, J. L. and Lovett Doust, L. L. (eds) Plant Reproductive Ecology: Patterns and Strategies, pp. 98-124. Oxford University Press, New York.

BERTIN, R. I. 1982. Paternity and fruit production in trumpet creeper. Am. Nat., 119, 694-709.

BERTIN, R. I. 1985. Nonrandom fruit production in Campsis radicans: between year consistency and effects of prior pollination. Am. Nat., 126, 750-759.

BOOKMAN, s. s. 1984. Evidence for selective fruit production in Asclepias. Evolution, 38, 72-86.

BREWBAKER, J. L. AND KWACK, B. H. 1963. The essential role of calcium ion in pollen germination and pollen tube growth. Am. J. Bot., 50, 859-865.

BROYles, s. B. AND WYATT, R. 1990. Paternity analysis in a natural population of Asclepias exaltata: multiple paternity, functional gender, and the "pollen-donation hypothesis". Evolution, 44, 1454-1468.

CAMPBEll, D. R., WASER, N. M., PRICE, M. V., LYNCH, E. A. AND MITCHELL, R. J. 1991. Components of phenotypic selection: pollen export and flower corolla width in Ipomopsis aggregata. Evolution, 45, 1458-1467.

CHARLESwORTH, D. 1988. Evidence for pollen competition in plants and its relationship to progeny fitness: a comment. Am. Nat., 132, 298-302.

CRUZAN, M. B. 1990a. Pollen-pollen and pollen-style interactions during pollen tube growth in Erythronium grandiflorum (Liliaceae). Am. J. Bot., 77, 116-122.
CRUZAN, M. B. 1990 b. Variation in pollen size, fertilization ability, and postfertilization siring ability in Erythronium grandiflorum. Evolution, 44, 843-856.

DANE, F. AND MELTON, B. 1973. Effect of temperature on self- and cross-compatibility and in vitro pollen growth characteristics in alfalfa. Crop Sci., 13, 587-591.

EMERSON, s. 1940. Growth of incompatible pollen tubes in Oenothera organensis. Bot. Gaz., 101, 890-911.

HAVENS, K. 1994a. Nonrandom Reproductive Success in an Endangered Evening Primrose (Oenothera organensis). Ph.D. Thesis, Indiana University, Bloomington, IN.

HAVENS, K. 1994b. Clonal repeatability of in vitro pollen tube growth rates in Oenothera organensis (Onagraceae). Am. J. Bot., 81, 161-165.

JEFFERSON, R. A. 1987. Assaying chimeric genes in plants: The GUS gene fusion system. Plant Mol. Biol. Rep., 5, 387-405.

JEFFERSON, R. A., KAVANAGH, T. A. AND BEVAN, M. w. 1987. GUS fusions: $\beta$-glucuronidase as a sensitive and versatile gene fusion marker in higher plants. $E M B O J ., 6$, 3901-3907.

LAND1, P. A. AND FRASCAROL1, E. 1988. Pollen-style interactions in Zea mays L. In: Cresti, M., Gori, P. and Pacini, E. (eds) Sexual Reproduction in Higher Plants, pp. 315-320. Springer-Verlag, Heidelberg, Germany.

LEE, T. D. 1988. Patterns of fruit and seed production. In: Lovett Doust, J. L. and Lovett Doust, L. L. (eds) Plant Reproductive Ecology: Patterns and Strategies, pp. 179-202. Oxford University Press, New York.

LEE, T. D. AND BAZZAZ, F. A. 1986. Maternal regulation of fecundity: Non-random ovule abortion in Cassia fasiculata. Oecologia , 68, 459-465.

LEWIS, D. 1948. Structure of the incompatibility gene. I. Spontaneous mutation rate. Heredity, 2, 219-236.

LYONS, E. E., WASER, N. W., PRICE, M. V., ANTONOVICS, J., AND MOTTEN, A. F. 1989. Sources of variation in plant reproductive success and implications for the concept of sexual selection. Am. Nat., 134, 409-433.

Marshall, D. L. 1988. Postpollination effects on seed paternity: mechanisms in addition to microgametophyte competition operate in wild radish. Evolution, 42, 1256-1266.

MARSHALL, D. L. AND Ellstrand, N. C. 1986. Sexual selection in Raphanus sativus: experimental data on nonrandom fertilization, maternal choice, and consequences of multiple paternity. Am. Nat., 127, 446-461.

MARSHALL, D. L. AND ELLSTRAND, N. C. 1988. Effective mate choice in wild radish: evidence for selective seed abortion and its mechanism. Am. Nat., 131, 739-756.

MAZER, s. J. 1987. Parental effects on seed development and seed yield in Raphanus raphanistrum: implications for natural and sexual selection. Evolution, 41, 355-371.

McKONE, M. J. AND Lively, C. M. 1993. Statistical analysis of experiments conducted at multiple sites. Oikos, 67, 184-186.

MULCAHY, D. L. 1971. A correlation between gametophytic and sporophytic characteristics in Zea mays L. Science, 171, 1155-1156.

MULCAHY, D. L. 1979. The rise of the angiosperms: a gene- 
cological factor. Science, 206, 20-23.

MULCAHY, D. L., CURTIS, P. S., AND SNOW, A. A. 1983. Pollen competition in a natural population. In: Jones, C. E. and Little, R. J. (eds) Handbook of Experimental Pollination Biology, pp. 330-337. Scientific and Academic Editions, New York.

NAKAMURA, R. R. 1988. Seed abortion and seed size variation within fruits of Phaseolus vulgaris: pollen donor and resource limitation effects. Am. J. Bot., 75, 1003-1010.

OTTAVIANO, E., SARI-GORLA, M., AND ARENARI, x. 1983. Male gametophytic competitive ability in maize: selection and implications with regard to the breeding system. In: Mulcahy, D. L. and Ottaviano, E. (eds) Pollen: Biology and Implications for Plant Breeding, pp. 367-373. Elsevier Science, New York.

PFAHLER, P. L., AND LINSKENS, H. F. 1972. In vitro germination and pollen tube growth of maize (Zea mays) pollen. VI. Combined effects of storage and the alleles at the waxy $(\mathrm{wx})$, sugary $\left(\mathrm{su}_{1}\right)$ and shrunken $\left(\mathrm{sh}_{2}\right)$ loci. Theor. Appl. Genet., 42, 136-140.

QUESADA, M., WINSOR, J. A. AND STEPHENSON, A. G. 1993. Effects of pollen competition on progeny performance in a heterozygous cucurbit. Am. Nat., 142, 694-706.

RICE, w. R. 1989. Analyzing tables of statistical tests. Evolution, 43, 223-225.

RIGNEY, L. P., THOMSON, J. D., CRUZAN, M. B., AND BRUNET, J. 1993. Differential success of pollen donors in a selfcompatible lily. Evolution, 47, 915-924.

ROCHA, O. J., AND STEPHENSON, A. G. 1991. Effects of nonrandom seed abortion on progeny performance in Phaseolus coccineus L. Evolution, 45, 1198-1208.

SARI-GORLA, M., OTTAVIANO, E. AND FAINI, D. 1975. Genetic variability of gametophyte growth rate in maize. Theor. Appl. Genet., 46, 289-294.

SCELONGE, C. 1989. The high efficiency transformation of Oenothera organensis by Agrobacterium tumefaciens. M.Sc. Thesis, Indiana University, Bloomington, IN.

SCHEMSKE, D. W. AND FENSTER, C. 1983. Pollen grain interactions in a neotropical Costus: effects of clump size and competitors. In: Mulcahy, D. L. and Ottaviano, E. (eds) Pollen: Biology and Implications for Plant Breeding, pp. 405-410. Elsevier Science, New York.
SCHOEN, D. J., AND STEWART, S. C. 1986. Variation in male reproductive investment and male reproductive success in white spruce. Evolution, 40, 1109-1120.

SNOW, A. A., AND MAZER, s. J. 1988. Gametophytic selection in Raphanus raphanistrum: a test for heritable variation in pollen competitive ability. Evolution, 42, $1065-1075$.

SNOW, A. A. AND SPIRA, T. P. 1991. Pollen vigour and the potential for sexual selection in plants. Nature, 352, 796-797.

STANTON, M. L., ASHMAN, T.-L., GALlOWAY, L. F., AND YOUNG, H. J. 1992. Estimating male fitness of plants in natural populations. In: Wyatt, R. (ed.) Ecology and Evolution of Plant Reproduction, pp. 62-90. Chapman and Hall, New York.

STEPHENSON, A. G. 1981. Flower and fruit abortion: proximate causes and ultimate function. Ann. Rev. Ecol. Syst., 12, 253-279.

STEPHENSON, A. G. AND WINSOR, J. A. 1986. Lotus comiculatus regulates offspring quality through selective fruit abortion. Evolution, 40, 453-458.

STEPHENSON, A. G. AND BERTIN, R. I. 1983. Male competition, female choice, and sexual selection in plants. In: Real, L. (ed.) Pollination Biology, pp. 110-151. Academic Press, New York.

STEPHENSON, A. G., LAU, T. C., QUESADA, M., AND Winsor, J. A. 1992. Factors that affect pollen performance. In: Wyatt, R. (ed.) Ecology and Evolution of Plant Reproduction, pp. 119-136. Chapman and Hall, New York.

VISSER, T. 1983. A comparison of the mentor and pioneer pollen techniques in compatible and incompatible pollination of apple and pear. In: Mulcahy, D. L. and Ottaviano, E. (eds) Pollen: Biology and Implications for Plant Breeding, pp. 229-236. Elsevier Science, New York.

WALSH, N. E. AND CHARLESWORTH, D. 1992. Evolutionary interpretations of differences in pollen tube growth rates. Q. Rev. Biol., 67, 19-37.

willson, M. F. 1979. Sexual selection in plants. Am. Nat., $113,777-790$

YOUNG, H. J., AND STANTON, M. L. 1990. Influences of floral variation on pollen removal and seed production in wild radish. Ecology, 71, 536-547. 